\title{
Pasión, arte y verdad en La Ciencia Jovial de Friedrich Nietzsche
}

\section{Passion, art and truth in The gay science by Friedrich Nietzsche}

\author{
Daniel Andrés Alegre \\ Estudiante de la Licenciatura en Filosofía \\ Universidad Nacional del Nordeste \\ andresalegre13@gmail.com
}

\section{Resumen}

La tradición exegética de la obra nietzscheana abunda en análisis acerca de las influencias románticas de las filosofías de Schopenhauer y Wagner sobre las obras de juventud de Nietzsche. Así mismo está bien estudiada la ruptura con dichas filosofías debido al desencanto del autor con sus maestros. En este trabajo buscamos rastrear en La ciencia jovial, obra del periodo ilustrado de Nietzsche, los conceptos derivados de la filosofía práctica romántica que en sí misma representó una variante de la imagen arquetípica que tenemos del romanticismo. Para esta exploración utilizaremos el concepto de pasión como eje estructurador. A partir de este concepto abordaremos su relación con la vida, el establecimiento de verdades, la vida en sociedad, la el mundo y finalmente con la voluntad de poder.

Palabras claves: Nietzsche, romanticismo, pasión, vitalismo, realidad.

\section{Abstract}

The exegetical tradition of the nietzschean work abounds in the analysis about the romantic influences of the philosophies of Schopenhauer and Wagner on the works of Nietzsche's youth. Likewise, the rupture with these philosophies due to the author's disenchantment with his teachers is well studied. In this work we seek to trace in The Jovial Science -work of the illustrated period of Nietzsche- the elements derived from the romantic practical philosophy that in itself represented a variant of the archetypal image we have of romanticism. For this exploration we will use the concept of passion 
as a structuring axis. From this concept, its relationship with life, the establishment of truths, life in society, the world and finally, the will to power are addressed.

Keywords: Nietzsche, romanticism, passion, vitalism, reality.

\section{Introducción}

Dividir la obra nietzscheana en los periodos romántico, ilustrado y de madurez es un lugar común a la hora de abordar el pensamiento de este filósofo. También lo es la creencia de que existe una oposición entre el periodo romántico y los que lo siguieron, lectura que el mismo autor se encargó de establecer. Este trabajo pretende demostrar que el periodo romántico o de juventud se proyecta sobre, al menos, el periodo ilustrado. Para ello, analizaremos en La ciencia jovial ciertas líneas conceptuales que parecen remitirnos al movimiento romántico.

Es por ello que la primera parte de este escrito ensaya un mapeo del campo romántico en cuanto movimiento estético-filosófico desde tres perspectivas: los estudios germánicos de estética, la historia del arte y por último desde los estudios hermenéuticos. De este modo se busca trazar las líneas de pensamiento útiles para relacionar al romanticismo con el periodo ilustrado de Nietzsche. En la segunda parte se aborda La ciencia jovial aplicando a la obra las claves de lectura anteriormente planteadas. La amplia gama temática tratada por el filósofo en esta obra nos obliga a tomar un concepto estructurador a partir del cual leerla. Este concepto es el de la pasión, hilo conductor que nos permitirá vislumbrar los matices románticos presentes en las ideas sobre el arte, la verdad, la vida, el hombre en relación con la sociedad y con el mundo.

\section{Un romanticismo nietzscheano}

El romanticismo como movimiento estético-filosófico no fue unívoco o uniforme, y en ocasiones tampoco delimitable a un periodo de tiempo, sino que pervive en algunas expresiones modernas (Hauser, 2006). Para abordar las relaciones entre el romanticismo y la filosofía nietzscheana es necesario dar cuenta de la diversidad de posturas que conformaron dicho movimiento. Para ello tomaremos las reflexiones de 
la autora Silvia Silveira Laguna respecto de las investigaciones realizadas por el germanista Paul Kluckhohn (1886-1957) sobre el romanticismo alemán y su relación con la filosofía vitalista. Esto nos permitirá marcar una distinción entre dos corrientes románticas con ideas acerca del mundo, el arte y la vida contrarias, para luego ensayar un posible acercamiento de la obra de Nietzsche a una de estas corrientes.

Dentro del romanticismo existen dos líneas marcadas de pensamiento. Es posible identificar por un lado a la filosofía idealista romántica y por otro a la filosofía práctica romántica. A estas dos corrientes les corresponderá dos concepciones distintas acerca del arte. La primera interpreta la obra de arte como representación de la vida, como mero reflejo de la realidad y muestra de lo vivo, de allí que se describa al arte como lebendig, es decir, como arte vivo. Por su parte, la segunda corriente entiende al arte como una representación vital, esto es, como producto de las fuerzas del espíritu que incluye la creación y superación respecto de la realidad representada, por ello se entiende al arte como lebenskunst, es decir, arte vital (Silveira Laguna, 1997). Esta última forma de entender el arte resulta especialmente esclarecedora para abordar las ideas de Nietzsche y su relación con el romanticismo, ya que pone de relieve el valor de la creación artística por su relación significativa con la vida, y por lo tanto, por su función de afirmación de la existencia.

Como dijimos, la idea de arte vital (lebenskunst) es una derivación directa de la filosofía práctica romántica que se contrapone a la filosofía idealista romántica.

Esta última forma es el pesimismo romántico por antonomasia, ya sea como filosofía de la voluntad schopenhaueriana o como música wagneriana (...) aún puede existir un pesimismo completamente distinto, un pesimismo clásico- he aquí una intuición y una visión que me pertenecen como algo inseparable de mí (...) Yo llamo a ese pesimismo del futuro iya viene! ¡Ya lo veo venir!-el pesimismo dionisíaco (Nietzsche, 2010, p. 579).

Esta escisión fundamental se da por la superación del Ser Absoluto, propio del idealismo, por un Ser Práctico que se concreta en la obra de arte por la libre capacidad creadora del sujeto, prescindiendo de toda explicación metafísica. En este sentido, 
queda claro la transición del idealismo romántico, metafísico y pesimista hacia el romanticismo práctico de un marcado corte vitalista (Silveira Laguna, 1997). Esta distinción ayuda a matizar la separación entre el romanticismo y la obra nietzscheana ya que el concepto romántico de arte, entendido en los términos arriba expuestos, "será la base de la voluntad de vivir que a su vez se perfecciona y engrandece en voluntad de poder, entendida como creatividad" (Silveira Laguna, 1997, p. 70).

Dentro del canon romántico alemán que expresa esta visión sobre el arte son especialmente significativos autores como Novalis, Friedrich Schlegel y Wilhelm Schlegel. Novalis parte de la consideración de la vida como el más alto y doloroso arte que tiene un marcado carácter activo, positivo y creador. Para este autor el arte es una unión entre el Yo y el Mundo en la que se expresa de una forma individualizada la esencia de la realidad, de modo que el artista es "creador de la obra de arte como sentimiento vital, resultado de un acto de experiencia consciente y libre, así el ser del mundo se hace vivo" (Silveira Laguna, 1997, p. 81). Por su parte, F. Schlegel define a la obra de arte como centro vital, es decir, como búsqueda, proyección y profundización de lo humano y del mundo. Deja afuera toda trascendencia y se centra en la actividad creadora como búsqueda de medios en los que proyectar la interioridad del artista. Por último, W. Schlegel considera a la obra de arte como una amalgama de ideas, pensamientos y sentimientos, es un medio para entender la realidad y conocer el mundo en sí mismo, cuya esencia es el dolor. El arte es la exteriorización de la vida, en este sentido, tiene realidad en sí mismo porque representa la esencia de la vida.

Para estos autores, innegablemente románticos, el arte es la conexión estética entre el sujeto y el mundo, sin un carácter metafísico, sino creativo-individual capaz de expresar lo humano y servir al conocimiento del mundo. Es posible ver en este movimiento la base para la posterior evolución estética de Nietzsche hacia el vitalismo, concepto que aquí nos interesa. Para Silveira Laguna la estética vitalista de Nietzsche parte del concepto romántico de arte como medio de conocer el mundo que "se despliega evolutivamente en una definición más amplia a lo largo de la obra nietzscheana, en el sentido de obra de arte como realidad vital" (Silveira Laguna, 1997, p. 90). 
Desde otra perspectiva, en la tradición de la historia del arte se ha marcado como característica propia del romanticismo la unilateralidad, la negación de la complejidad y de la tensión de fuerzas externas presentes en la dialéctica histórica en pos de una proyección del yo sobre la realidad, lo que se traduce en una reacción exagerada delatora de un desequilibrio espiritual, lo que Arnold Hauser ha llamado principio de enfermedad del romanticismo:

La enfermedad suponía para ellos (los románticos) la negación de lo ordinario, normal y razonable, y contenía el dualismo de vida y muerte, naturaleza y no naturaleza, continuación y disolución, que dominaba toda su imagen del mundo. Ella significaba la depreciación de todo lo unívoco y permanente y correspondía a la repulsión romántica de toda limitación y toda forma sólida y definitiva (Hauser, 2006, p. 197).

Este desequilibrio sobrevivirá en Nietzsche como nota característica de los espíritus superiores por lo que implica el constante movimiento, en contraposición con la quietud de las leyes, con el equilibrio estático del concepto, en definitiva, por la elección del devenir por sobre el ser:

El más rico en plenitud vital, el dios y el hombre dionisíacos, no sólo es capaz de permitirse el espectáculo de lo terrible y de lo problemático, sino también de cometer acciones terribles y entregarse al lujo de la destrucción, descomposición y negación; en él, el mal, lo insensato y lo espantoso, parece, por así decirlo, permitido, a consecuencia de un exceso de fuerzas productoras, fértiles, capaces incluso de crear una abundante tierra fértil en cualquier desierto (Nietzsche, 2010, p. 577).

El hombre superior es aquel que posee la voluntad de vivir, fuerza creadora que pone al sujeto como responsable de su propio existir, entendido como acción constante de creación, es decir de la superación de la metafísica por el arte. En esto también se advierte aquel paso del ser absoluto hacia un ser individual, pues Nietzsche 
se presenta como un corte con el idealismo romántico en el que subyace un dualismo, y su filosofía puede relacionarse con lo que más arriba se describió como filosofía práctica romántica:

Hoy en día, nosotros, los filósofos del presente y los del futuro, somos todos sensualistas, no según la teoría, sino según la praxis, la práctica... Aquellos (los filósofos del pasado) pensaban, por el contario, que los sentidos seducían a alejarse de su mundo, el frío reino de las "ideas" (...) un auténtico filósofo dejaba de escuchar a la vida: en la medida que la vida es música, negaba la música de la vida (Nietzsche, 2010, p. 582).

Por otro lado, aproximaciones desde la hermenéutica como la de Andrés OrtizOsés plantean el carácter equilibrado de la filosofía del joven Nietzsche en contraposición al desequilibrio de la obra posterior. Este autor califica a la obra nietzscheana como pos-romántica. Según él, la obra temprana denota un equilibrio entre la fuerza dionisíaca y apolínea encarnado por el punto medio entre ambos dioses, que sería el dios Hermes. Este equilibrio se da por un movimiento de la fuerza matriarcal originaria (Dionisio) hacia la fuerza/forma patriarcal posterior (Apolo) encargada de sublimar el abismo del ser que representa el primero. Este proceso dialéctico se completa con el movimiento de regreso desde lo apolíneo a lo dionisíaco, de lo patriarcal-racional a lo matriarcal-naturalista. De aquí que en medio de estas fuerzas esté Hermes, el dios del lenguaje, la comunicación y la mediación como fuerza reconciliadora entre los movimientos de ascensión y descenso (Ortíz-Osés, 2012). Ahora bien, en el desarrollo de su obra, como ya dijimos, Nietzsche evoluciona hacia el vitalismo, y en esta transición ocurre el desequilibrio romántico, según el cual la balanza se inclina contundentemente hacia el sentido dionisíaco de la existencia:

Lo que subyace a esta filosofía (la tardía) es la sobre afirmación de la vida y su sacralización en todos sus extremos, la eternización del devenir reconvertido así en ser, la santificación de todas y cada una de las cosas en un Todo que todo lo contiene y consagra. La tesis del 
"eterno retorno" de todas las cosas es la afirmación del mundo considerado como su propio trasmundo, cuyo dios es el propio Dionisio inmanente y no un dios trascendente. Ahora el auténtico dios nietzscheano es una divinidad que comprime en sí la plenitud de antagonismos de la vida, redimiéndolos y justificándolos en su trasfiguración divina. Al bendecir así el todo de la vida se bendicen sus partes, al asumirlo bueno asumimos también lo malo, al decir sí acogemos el no (Ortíz-Osés, 2012, p. 81).

Como podrá verse, en el romanticismo entendido dentro de los límites establecidos por los autores propuestos ya se encuentran contenidas varias de las postulaciones que en la obrade Nietzsche tomarán la forma del vitalismo. Si bien es un lugar común de la crítica pensar que sólo su obra de juventud fue influida por el romanticismo, interpretación que el mismo autor se encargó de establecer, es posible entrever un núcleo conceptual en común con dicho movimiento estético-filosófico y que luego él se encargará de desarrollar genialmente.

\section{La pasión como fundamento de la vida}

\section{La pasión en La ciencia jovial}

La categoría que pretendemos abordar y que nos permite entrever los resabios románticos que hay en la obra nietzscheana, específicamente en La ciencia jovial, es el concepto de pasión. El despliegue de la vida ocurre mediante el despliegue de la pasión. Ese cúmulo de sentimientos, disposiciones, motivaciones, etc. a menudo contradictorios luchan entre sí para afirmarse frente a los demás instintos. Este elogio del hombre que da rienda suelta a las pasiones dará en Nietzsche grandes frutos, ya que en el desarrollo de su obra el vitalismo será una base fecunda para la tardía formulación del concepto de voluntad de poder.

No obstante, ya en el periodo ilustrado, más concretamente en La ciencia jovial es posible rastrear cierta voluntad de mando como tono característico del hombre superior, aquel que no le teme a sus propias pasiones. Cabe entender este despliegue 
de la pasión dentro del principio de desequilibrio con el que caracterizamos a cierto tipo de expresiones románticas:

Estas manifestaciones paradójicas, como por ejemplo, la súbita frialdad que irrumpe en el comportamiento de hombres de temperamento, o como el humor del melancólico (...) aparecen en hombres que poseen una poderosa fuerza interna desbordante, capaces de experimentar una repentina sensación de saciedad y de repentina náusea (...) a este repentino desenfreno le sigue una enorme y repentina náusea (...) sólo está cediendo al nuevo instinto que precisamente a hora se ha vuelto poderoso en él (Nietzsche, 2010, p. 376).

Así pues, mediante la contraposición de instintos se libera la convulsión sentimental. Esta liberación es a su vez el más alto estímulo para el intelecto. Mediante una economía de las fuerzas que se da entre la acumulación y la liberación se hace manifiesta la verdadera naturaleza del espíritu:

De estos dos oradores, uno alcanza toda la razón de su causa cuando se abandona a la pasión. Sólo ésta es capaz de bombearle suficiente sangre y calor hacia el cerebro para obligar a que su gran intelecto se revele (...) Sólo entonces es cuando su espíritu sale por completo de su escondite (Nietzsche, 2010, p. 411).

Ahora bien, es evidente que quien viva de acuerdo al dictado de sus pasiones está en un inmenso peligro, pues la consecuencia de vivir sin tapujos, de hacer conscientes las propias contradicciones es un inmenso dolor y asco. Pero el dolor no es en sí malo ni perjudicial, posee cierto grado de utilidad en cuanto a la preservación de la especie. El dolor nos advierte de cuándo debemos vivir con las fuerzas reducidas. Sin embargo, existe cierta clase de hombres que frente al peligro buscan aumentar sus fuerzas, son estos los que realmente hacen avanzar a la especie, los que poseen la experiencia vital. En este sentido, el vitalismo consiste en ese despliegue de las pasiones que trae aparejado dolor, es también confrontar y atravesar ese el dolor y entenderlo como un 
elemento más, igualmente necesario para la vida. El vitalismo no sólo es un avanzar, una afirmación, sino que también contiene en sí la negación; para que la vida se despliegue es necesaria la muerte, la extinción de ciertas fuerzas:

Vivir, esto significa: derribar continuamente algo de uno mismo que quiere morir; vivir, esto significa: ser cruel e implacable contra todo lo que se vuelva débil y viejo dentro de nosotros. Vivir, significa pues: ¿no tener piedad con lo que muere, con la miseria, con el anciano? (Nietzsche, 2010, p. 361).

Al final del aforismo arriba citado Nietzsche se pregunta irónicamente “¿Ser siempre asesinos? ¡Pero si el viejo Moisés dijo: No matarás!” (2010) y es que la tradición judeo-cristiana representa un cambio de actitud frente a las pasiones respecto de los griegos. Estos últimos amaron las pasiones, las divinizaron, eran para ellos fuente de pureza. Para los judeo-cristianos, en cambio, las pasiones son un obstáculo para llegar al paraíso prometido. La aniquilación de las pasiones es un paso necesario para la purificación, para entrar en contacto con lo divino.

Detrás de esta búsqueda por reprimir las pasiones, Nietzsche ve el deseo de reprimir sólo su expresión, su lenguaje y gesto, pero lo que se logra es sólo debilitarlas o transformarlas. La consecuencia más notable de esta educación en la represión, característica de las generaciones anteriores, es que el hombre se volvió incapaz de percibir la naturaleza de sus propias pasiones. Le compete al hombre del futuro vivir sus pasiones no como algo vulgar, como se las ha vivido, sino como el verdadero fundamento de la vida.

Esto nos lleva a considerar la crítica nietzscheana a la pasión formal. Es decir a la pasión propia de los actores, al fingimiento de la voluptuosidad en pos de la apariencia de refinamiento y nobleza. Nietzsche ve en el arte del teatro un anhelo de sufrimiento, esto es, la representación tosca y burda del drama de la vida, un juego de máscaras que involucra a actores y espectadores (actores también) en la búsqueda del impulso vital en el sufrimiento. Esta clase de hombres ven en el mundo la fuente de su infelicidad pues "ha de existir en ellos un ansia de sufrir para extraer de su sufrimiento una supuesta razón para emprender alguna obra o acción. ¡Es preciso que exista la 
miseria!" (Nietzsche, 2010, p. 361). De esta manera se despega de las más vulgares expresiones de sentimentalismo pues el verdadero apasionado hace de su vida su propio teatro de tragedias y comedias.

Es comprensible que en un mundo en el que las pasiones son reprimidas se tome por verdaderas las pasiones fingidas, aparentes, innobles. Se cree que el dolor nos engrandece, nos hace superiores, pero en realidad, el apasionado, sabe que sólo es una condición para la vida. Debido a que la tradición cristiana establece que esta vida es sólo dolor, que la pasión es la causa del mal estado de la humanidad y que es necesario aniquilarla para alcanzar la pureza y la felicidad, el hombre, por su inagotable talento para procurarse placeres, halló placer en la debilidad, la represión, el dolor. Frente al mandamiento moral "Tu virtud es tu salud" que establece la represión de las pasiones como sinónimo de salud, Nietzsche ensaya la proposición: “No existe una salud en sí misma (...) lo que importa es tu meta, tu horizonte, tus fuerzas, tus impulsos, tus errores y, especialmente, los ideales y fantasmas de tu alma" (2010, p. 435). El hombre del futuro tiene el deber de reflexionar acerca de la salud y de la enfermedad del alma e "identificar la virtud más propia para la salud individual: la cual, ciertamente, aparecerá en uno como opuesta a la salud de otro" (2010, p. 435). Otra vez, he aquí el interés sobre el ser individual-práctico en detrimento de un ser absoluto. En este movimiento el filósofo también problematiza la negatividad de la pasión, la enfermedad como parte del proceso vital:

\section{Queda sin contestar la gran pregunta acerca de si podríamos realmente abstenernos de la enfermedad, incluso para el desarrollo de nuestra propia virtud, y de si, a nivel particular, nuestra sed de conocimiento y de autoconocimiento no necesita tanto del alma enferma como de la sana (Nietzsche, 2010, p. 438).}

Más aún, la pasión, según Nietzsche es fundamental para quien busque conocer. En contraposición a la tradición filosófica que opone el conjunto de las pasiones humanas a la idea de entendimiento, él considera que el acto de entender es la última instancia en la que se llega a sentir al mismo tiempo la risa, el llanto, el odio, etc., es el resultado de la lucha de instintos diferentes y contradictorios que buscan afirmarse en su 
existencia. En este sentido, el pensamiento filosófico, según Nietzsche (2010) es el que más probablemente persista en el error, ya que habitualmente los filósofos carecen de la pasión necesaria para conquistar el conocimiento. Los problemas filosóficos necesitan ser abordados con el ímpetu de la pasión "una personalidad debilitada, floja, apagada, que se niega y reniega de sí misma, ha dejado de servir para algo bueno -y menos aún para la filosofía" (2010, p. 575).

De este modo, Nietzsche invita a los filósofos del futuro a conquistar el saber, a desplegar sus pasiones, a vivir la vida como un experimento y no como una mera fatalidad o un transitar, una fuga hacia otro mundo. Mediante la pasión, es posible, según él, entender a la vida como un medio de conocimiento y "con este acierto en el corazón no sólo se puede ser valiente, sino incluso vivir jovialmente y reír jovialmente" (2010, p. 515).

\section{Arte y verdad}

El concepto de arte en Nietzsche está profundamente relacionado con el de voluntad de poder. Esta última categoría por demás escurridiza escapa a los alcances de este trabajo, sin embargo, autores como Martín Heidegger (2000) la entienden como el deseo básico de incrementación del poder en la naturaleza, esto incluye tanto a los seres orgánicos como a los inorgánicos. Para Heidegger la voluntad de poder es esencialmente devenir, por ello es lo que caracteriza al ente (pero no lo define) y en tanto voluntad es voluntad de sí misma, un constante quererse a sí misma. Es importante aproximarnos a la idea de voluntad de poder ya que es ella la que fundamenta a la pasión, al afecto y al sentimiento. Éstos no son más que "configuraciones" de la voluntad de poder que dan testimonio de su acrecentamiento, lo así llamado plenitud o estado de embriaguez (Silenzi, 2006).

El arte genera en el hombre este estado de embriaguez, pero no en el espectador, sino en el artista. Es por ello que Nietzsche aborrece a los artistas que tratan de trasladar o hacer surgir en el espectador la embriaguez, pues no lo considera deseable: "sé muy bien qué música y qué arte no hubiera querido, a saber: toda la que intenta embriagar a quienes la escuchan y les eleva a un momento de sentimiento intenso y 
sublime..." (2010, p. 403). Él cree que el arte está ligado directamente a la vida y que aquella manera de entender el arte como exterior al sujeto, como espectáculo, constituye un alejamiento de la vida: “¿No son éstos [los espectadores] hombres para los que la vida no es una acción, sino un negocio (...)?" (p. 403) "Ahora, con las obras de arte se busca apartar de la gran calle del sufrimiento de la humanidad, a pobres agotados y enfermos: se les ofrece un momento agradable y de enajenación" (p. 406). También aborrece a los artistas que no hacen más que "glorificar todas esas situaciones y cosas que tienen la fama de dar al hombre la oportunidad de sentirse por una vez, en ella y gracias a ellas, bueno, o grande o ebrio o contento o sano y sabio" (p. 403).

Además de abordar la equivalencia entre arte y vida, Nietzsche sitúa su reflexión estética desde la perspectiva del artista, a diferencia de la tradición filosófica que lo hizo desde el espectador o bien desde la obra: "Para quien él mismo es algo de Fausto o de Manfredo, ¿qué le importan los Faustos o los Manfredos del teatro?" (p. 404).

No conozco ninguna diferencia más profunda en la óptica entera de un artista que esta: si éste mira partiendo de la óptica del testigo que contempla su obra de arte en progreso (viéndose a "sí mismo"), o si, por el contrario "ha olvidado el mundo", como caracteriza a todo arte monológico-descansando en el olvido, constituye la música del olvido (p. 573).

La experiencia estética del artista es una experiencia corporal, en tanto que el cuerpo no sólo es biología, sino también un amasijo de instintos, pulsiones, voliciones, sentimientos y deseos.

La falsedad con buena conciencia, ese placer por la simulación que irrumpe poderosamente y desplaza a un lado al llamado "carácter" (...) ese íntimo deseo de penetrar en un papel, en una máscara, en una apariencia; ese exceso de facultades adaptativas de todo tipo, que ya no saben satisfacerse al servicio de la más inmediata y estrecha utilidad (...) a la postre, toda esa capacidad acumulada de 
generación en generación se convierte, finalmente, en tiránica, irracional, indomable, y, como instinto, aprende a mandar a otros instintos, y produce al actor, al artista... (p. 567)

De esta manera el arte lo acerca al mundo, le permite acceder a la "visión" de la vida (mundo). En este sentido también es deseo de voluntad, pues pone de manifiesto el atractivo de lo imperfecto, es decir que es una falta y un anhelo de crear los estados de plenitud: “...en su alma [del poeta] subsiste el enorme apetito por esta visión, gracias a ella, obtiene también la enorme elocuencia de su deseo y apetito" (p. 394). A través de la embriaguez, y del deseo de embriaguez, el artista puede ver los trazos capitales de las cosas, por ello el arte tiene más valor que la verdad, puesto que es un espacio para la libertad y la creación de nuevas emociones e ideas, mediante él se vislumbran los límites del ente. El arte, en todo su sentido etimológico, es la capacidad de producir cosas, de otorgarle ser a lo que no lo tiene.

En este sentido, el arte marca un claro alejamiento de la naturaleza, más no de la vida. Tiene la capacidad de crear realidades y subvertir los valores. He aquí su importancia para Nietzsche: mediante él se pueden crear nuevos valores, es en definitiva el contramovimiento por excelencia frente al nihilismo.

Mediante el arte se crea subjetividades: "Sólo los artistas (...) han sido quienes han proporcionado a los hombres ojos y oídos para escuchar y ver (...) lo que cada uno es, vive y quiere por sí mismo..." (p. 393) y frente a los valores universales tan amados por los realistas, Nietzsche opone la voluntad de apariencia, es decir, el alejamiento de la naturaleza mediante el arte:

Este tipo de desviación de la naturaleza es tal vez el plato más agradable para el orgullo humano; por su causa, además, ama en general el arte como expresión de una suprema y heroica falta de naturalidad y convencionalismo (...) ¡Es aquí donde debe ser contradicha la naturaleza! ¡Es aquí precisamente donde debe retroceder el encanto vulgar de la ilusión a favor un encanto superior! (p. 395). 
En tanto que el arte tiene más valor que la verdad, es también el mayor estimulante para vida, la hace más ligera, nos libera del peso de la moral y de la ciencia: "Como fenómeno estético, la existencia nos sigue siendo todavía soportable, gracias al arte se nos regalan los ojos y las manos y, sobre todo, la buena conciencia para poder hacer de nosotros mismos un fenómeno semejante" (p. 423). Es decir que no se niega los sentidos, este mundo que podemos ver, tocar y sentir tiene valor en sí mismo y no en función de un mundo trascendente depositario de la verdad, el bien, la justicia, etc.

En reemplazo de estos valores universales, Nietzsche pone al arte y al artista como modo de vida y hacedor de nuevos valores, el arte como buena voluntad de apariencia ya que si todo es factible de ser interpretado, lo universal debe permanecer en suspenso, o más bien, nosotros debemos suspendernos, hacer equilibrio, sobre ellos "no con la angustiada rigidez de quien en cada instante teme resbalar y caer..." (p. 423) sino como quien sabe que esa es su condición de existencia y quiere jugar con ella.

El hombre ha alcanzado trascenderse a sí mismo, logrando de este modo dar cuenta de su subjetividad y de la distancia entre ésta y la realidad. Es decir, ha tomado conciencia de la relatividad de sus conocimientos, se ha vuelto desconfiado. La certeza ahora entra dentro de la esfera de la creencia, la fe, que a su vez representa el Bien. Frente a la creencia (bondad) el hombre ha erigido la ciencia, la malevolencia de la duda. Sin embrago, Nietzsche declara que su intención es demostrar la pertenencia natural del hombre a la esfera del bien. En efecto, superada la época de las certezas, transformamos a la ciencia en una necesidad, y para que algo sea necesario indefectiblemente debemos creer en ello.

La ruptura con las certezas trajo aparejada infelicidad y hartazgo para el hombre, en este panorama la ciencia suscita asombro, así como una "felicidad profunda y fundamental” (p. 373). Los descubrimientos de la ciencia producen asombro porque son aparentemente sólidos, inmutables y tienen una proyección hacia el futuro, es decir, dejan abiertas puertas para nuevos hallazgos y caminos por los que transitar. El hombre antiguo creía en la necesidad de su existencia, la centralidad de su mirada estaba sostenida por la costumbre en sentido amplio, por la eticidad. Esta creencia 
también causaba hastío, por ello, el hombre antiguo escapaba hacia lo maravilloso. Los cuentos e historias de hadas le permitían entrar en un plano de experiencia en el que no cargaba con el peso de las reglas y de la eternidad. Esta misma felicidad y asombro es lo que experimenta el hombre moderno ante los resultados de la ciencia, si antes se pasaba de lo firme a lo arbitrario, ahora se cree pasar de lo arbitrario a lo firme, delatando así el sentido cíclico de este pasaje y lo fundamentalmente humano de dicha felicidad. En efecto, pareciera que el hombre necesitara siempre nuevos ídolos en los que depositar su fe, siendo esta una constante de la naturaleza humana.

El encuentro con la propia subjetividad devela lo ancestral en nuestras costumbres, cómo lo que nos viene dado opera en nuestros juicios y conforma nuestros más profundos instintos. Ahora bien, una vez que adquirimos perspectiva y nos alejamos de nosotros mismos para conocernos mejor no podemos hacer otra cosa que resignarnos. La vida exige y norma las apariencias, el hecho de conocerlas y reconocernos soñadores entra en la lógica del sueño. Sin embargo, ser conscientes de estar soñando y del imperativo de seguir haciéndolo nos otorga una nueva perspectiva sobre la naturaleza de las apariencias: no hay nada más allá de ellas. Detrás de las máscaras sólo hay otras máscaras. El despertar sólo sirve para contemplar y asegurar otro sueño. Tras la duda sólo se oculta la fe y ésta, como sabemos, sólo engendra más dudas. De esta forma matamos al rey pero no destruimos el trono, por lo que siempre habrá alguien que lo reemplace.

En suma, luego de que el hombre se convenciera de la mutabilidad de las cosas humanas se volvió desconfiado, paradójicamente depositó su fe en un nuevo cuento de hadas, la ciencia, esperando que ésta, con sus simulacros de inmutabilidad lo sacara del limbo de la fe y le devolviera, como un espejo, su rostro. Sin embrago, la ciencia como autoconocimiento, como despertar del sueño no parece ser capaz de alcanzar una verdad. Como en un juego de cajas chinas, las máscaras se desarman, desintegran, caen, sólo para revelar nuevas máscaras. De hecho, la apariencia se vuelve el principio activo, el conocedor contempla cómo las máscaras son ahora su rostro.

\section{El hombre, la sociedad y la naturaleza}


El pensamiento filosófico se ha atribuido el logro de abstraer las "formas" separándolas del alma. Según Nietzsche esta separación halla su razón en el cúmulo de las pasiones: en el amor, el odio, el deseo, y demás sentimientos. Tan pronto el hombre siente que la naturaleza se ha entrometido con su posesión, ha negado la divinidad de las metas hacia las cuales lo empujan sus pasiones. El hombre se ha valido del sueño como medio de disimular la naturaleza, de negarla. Este rasgo de vulgaridad sigue presente en el hombre de hoy, el espíritu y fuerza del sueño persisten en el acto de disimular las funciones naturales mediante la creación de certidumbres, impulsada en realidad, por pasiones que nosotros mismo desconocemos.

Esta relación estética con el mundo, en la que nos posicionamos como artistas/artífices de la verdad, responde a un instinto marcadamente humano: el instinto de rebaño. El temor al aislamiento, a la soledad, nos hace aceptar juicios ajenos a nuestra conciencia, porque en la lucha entre las pasiones individuales (debilitadas) y el "sentimiento moral" ha ganado este último. De aquí que Nietzsche llame mentirosos por añadidura a quienes se rinden ante el instinto de conservación, ya que estos inventan razones para enmascarar el automatismos de dicho juicios y disimular el carácter convencional de las costumbres.

Quienes no sucumben ante el instinto de rebaño son los que marcan cada vez más su individualidad, los protagonistas de las épocas que la religiosidad denuncia como corruptas. La corrupción es síntoma de un estado en el desarrollo social en el que el alma se libera, aumentan la fuerza y violencia de las pasiones y se avanza intelectualmente hacia una ilustración. Las pasiones actúan como relajantes de las creencias, éstas se retrotraen a una forma de superstición. En este estado de liberación de las energías individuales no desaparecen la maldad ni el placer por la maldad (promesa del racionalismo) sino que se refinan resultando en la emergencia de los tiranos.

Los tiempos corruptos son aquellos en los que maduran los hombres superiores, frutos del árbol del pueblo, aquellos que viven sus pasiones sin temor a ellos mismos ni a los juicios ajenos a sí. Son productos del aumento de la individualidad, debido al descubrimiento del ego que luchó por imponerse a la voluntad de otros egos. 
Los tiempos corruptos son tiempos en los que las manzanas caen del árbol: quiero decir, los individuos, los que llevan dentro de sí las semillas del futuro, los autores de la colonización espiritual y de la nueva formación de comunidades, de estados y sociedades (p. 359).

El hombre de hoy, en cambio, carece de una filosofía de carácter afirmativo debido a las filosofías pesimistas que teatralizan la existencia y el dolor. Este pensamiento es fruto de la falta de ejercicio del dolor físico que experimentaba el hombre en otras épocas marcadas por la necesidad. La modernidad con sus comodidades eliminó la necesidad de entrenarse en el dolor, de conocer el cuerpo y el alma, por ello la sociedad se volvió extremadamente sensible y teatral. De este modo, al borrar la relación del dolor con la supervivencia, se negó también el conocimiento del cuerpo. Según Nietzsche esto se condice con la negación de este mundo, propia de la tradición cristiana: "La resolución del cristianismo de ver en el mundo algo feo y malo ha hecho del mundo algo feo y malo" (p. 444). En contraposición, él considera que la nobleza, la superioridad del hombre consiste justamente en la entrega jovial y despreocupada a las pasiones, pues quien sea capaz de ello no se temerá a sí mismo, será el verdadero apasionado, filósofo del futuro.

Como se dijo, la mejora en las condiciones de la vida tiene como consecuencia el debilitamiento de las pasiones. La sociedad hace del hombre un ser apacible. La forma para suplir esta carencia es el arte, éste es un narcótico que en tanto producto cultural ayuda a reemplazar el impulso vital perdido mediante el fingimiento. Si las personas se volvieron incapaces de experimentar otra cosa distinta del mero entusiasmo, el arte se vuelve el medio para encausar ese entusiasmo y suplir la falta de grandes pasiones.

Sin embargo, Nietzsche advierte la necesidad de dar cuenta de esta actividad creativa del hombre respecto de la naturaleza. Debemos abstenernos de asociar a la naturaleza atributos humanos, pues no es una máquina, no es azarosa porque no se rige por leyes, no tienen un destino, en fin, no es un ser viviente. En el universo no existe todo aquello que le impone el hombre desde su estética antropomórfica: orden, organización, forma, belleza, sabiduría, etc. 
A pesar del intento del cristianismo de negar este mundo, el hombre superior es consciente de su incapacidad de ver en la naturaleza algo distinto de sí mismo. Es decir, sabe que el acto de conocer, de avanzar sobre el territorio de las cosas es en realidad un autoconocimiento, ya que es un acto en el que reconocimiento de lo idéntico a sí mismo. Afirmada la convicción nietzscheana de lo inhumano del mundo, es decir del proceso de antropomorfización de la naturaleza propia de la "voluntad de veneración" del hombre queda clara la idea de no diferencia entre el hombre y la naturaleza. El hombre para Nietzsche no es el principio que niega la naturaleza ni puede erigirse el juez inquisidor de la naturaleza, ya que eso es propio de filosofías pesimistas:

\begin{abstract}
Nos hemos vuelto conscientes, y no sin repulsión, de la enorme falta de gusto en todas esas actitudes del "hombre contra el mundo", del hombre como principio que "niega al mundo", del hombre como medida del valor de las cosas, como juez del mundo, que, en definitiva, coloca a la propia existencia sobre su balanza y la encuentra demasiado ligera (p. 540).
\end{abstract}

De este modo, el reconocimiento de las pasiones que operan en el hombre y en su conocimiento acerca del mundo le hace ver que este no tiene el valor que pensaba. Se llega así a la conclusión de que el mundo en el que vive no es divino, ni inmortal, es inhumano.

\title{
La voluntad de poder
}

Como se vio más arriba, Nietzsche concibe la relación estética del hombre con el mundo en dos dimensiones. Por lado, el aspecto creativo, mediante el arte y la antropomorfización del mundo, el hombre crea/transforma el mundo a su imagen y semejanza. Por otro lado, la pretensión de humanizar el mundo estructura la capacidad de conocer de determinada manera, por lo que el intelecto humano sólo puede acceder al aspecto del mundo que le es semejante. De esta manera los espíritus superiores reconocen sus pasiones como parte de la naturaleza y las liberan: 
Son las naturalezas fuertes y ávidas de dominio las que disfrutan del deleite más sutil en esa presión, en esa sujeción y perfeccionamiento bajo la propia ley: la pasión del poderoso queda aliviada ante el espectáculo de lo natural sometido a estilo, de toda naturaleza vencida y domada (p. 492).

Mediante la liberación de las fuerzas naturales del espíritu, estas son las pasiones, el hombre puede conocerse a sí mismo "uno ha de poder perderse a sí mismo durante cierto tiempo, si quiere aprender algo de las cosas que él mismo es" (p. 505).

Contener las pasiones, el deseo de posesión, es signo de una necesidad de conservación, es pues "una limitación al instinto fundamental de la vida, que aspira a la ampliación del poder, y que, al desearlo, cuestiona y sacrifica muy a menudo la autoconservación" (p. 544). La voluntad de poder es el anhelo de vivir en toda su extensión los valores y posibilidades que brinda el mundo, es el deseo de experimentar la gran salud, sentimiento que se conquista continuamente disputándoselo a otros y luego se abandona.

Es mediante la voluntad de poder que se ponen en juego todos los conceptos arribas expuestos: la pasión y la vida, la pasión y la verdad, la pasión y el mundo. El romanticismo ha servido como campo fértil para la evolución genial del pensamiento nietzscheano que partió explicando el mundo en términos de dos fuerzas contrapuestas y decantó en un auténtico vitalismo en el que fuerzas múltiples luchan por el dominio de la existencia.

\section{Conclusión}

Es un lugar común de la tradición filosófica considerar que sólo la obra temprana de Nietzsche posee influencias románticas. Como hemos visto, es posible trazar una línea de continuidad entre cierta tradición del romanticismo filosófico, más específicamente de la filosofía práctica romántica en la que se encuentran los núcleos conceptuales que el autor de La ciencia jovial desarrollará de manera original.

El legado romántico de autores como Novalis y los hermanos Schlegel es fundamental para entender la evolución de Nietzsche hasta arribar al concepto de 
vitalismo. Como se ha podido observar, en este desarrollo cobra gran importancia el concepto de pasión, ya que es la piedra basal de la relación con el mundo y con el arte.

El arte es una embriaguez y una voluntad de vivir, es el gran seductor de la vida. Su tarea es intentar que no perezcamos a causa de la verdad. Por ello el mundo empírico se nos presenta como antropomórfico, detrás de él sólo hallaremos un cúmulo de pasiones y apetitos. En definitiva, la propuesta de Nietzsche es habitar románticamente el mundo, no como expresión del hombre (concepción vulgar del romanticismo) sino como voluntad de poder, con fuerzas activas desatadas que dicen sí a todo aquello que fluye por debajo del orden racional.

\section{Bibliografía}

Hauser, Arnold (2006). Historia social de la literatura y el arte, vol. 2. Debate, Buenos Aires.

Heidegger, Martin (2000). Nietzsche, vol. I, trad. Juan Luis Vermal. Ediciones Destino, Barcelona.

Martínez-Liébana, Ismael (1998). Perspectivismo y vitalismo: un ensayo de superación de escepticismo e idealismo. En: Revista de Filosofía, III vol XI. Servicio de publicaciones Universidad complutense, Madrid. Recuperado de: http://revistas.ucm.es/index.php/RESF/article/view/RESF9898120245A

Nietzsche, Friedrich (2010 [1882]). La Ciencia Jovial. Gredos, Madrid.

Silenzi, Marina (2006). El arte como nuevo pensar: la visión nietzscheana y heideggeriana. En: Andamios. Revista de Investigación Social, vol. 2, núm. 4, pp. 201-217. Universidad Autónoma de la Ciudad de México. Recuperado de: http://www.redalyc.org/articulo.oa?id=62820408

Silveira Laguna, Silvia (1997). Nietzsche: comprensión estética de la realidad vital. En Anales del seminario de Historia de la filosofía. Servicio de Publicaciones Universidad Complutense, Madrid.

Recuperado

de: http://revistas.ucm.es/index.php/ASHF/article/view/ASHF9797110073A 
Uicich, Sandra Marcela (2005). El mundo como representación en Nietzsche: antropomorfismo, metaforización y arte. En: Actas de las jornadas de Humanidades e Historia del Arte. Universidad Nacional de Bahía Blanca. Recuperado de: http://repositoriodigital.uns.edu.ar/handle/123456789/3507

Viviani, Teresa (2000). El arte en Nietzsche como el más alto estímulo de la vida. En: Aisthesis. Revista Chilena de Investigaciones Estéticas, núm. 33, pp. 176-184. Pontificia Universidad Católica de Chile. Recuperado de: http://revistaaisthesis.uc.cl/index.php/rait/issue/view/67/showToc

Ortiz-Osés, Andrés (2012). Nietzsche: la ilustración romántica. En: Solares Altamirano, Blanca (edit.) Mito y Romanticismo. UNAM, México. Recuperado de: https://www.crim.unam.mx/web/node/2344 